\title{
International Business Cycle Spillovers since the 1870s
}

\author{
N. Antonakakis*† \\ H. Badinger $\ddagger \S$
}

June 17, 2014

\begin{abstract}
This paper considers the evolution of international business cycle interdependencies among 27 developed and developing countries since the beginning of 1870 s, utilising the generalized VAR-based spillover index of Diebold and Yilmaz (2012), which allows the construction of a time-varying measure of business cycle spillovers. We find that, on average, $65 \%$ of the forecast error variance of the 27 countries' business cycle shocks is due to international spillovers. However, the magnitude of international business cycle spillovers varies considerably over time. There is a clear increasing trend since the end of World War II and until the mid-1980s. After that, international business cycle interdependencies declined during the period that was dubbed the Great Moderation, and stabilized around the beginning of the 21st century. During the Great Recession of 2008-2009, international business cycle spillovers increased to unprecedented levels. Finally, developed countries are consistently ranked as net transmitters of cyclical shocks to developing counties throughout the sample.
\end{abstract}

Keywords: Business cycle, Spillover, Variance decomposition, Vector autoregression, Developing country, Developed country

JEL codes: C32; E32; F01; F62; N10

${ }^{*}$ Corresponding author: Vienna University of Economics and Business, Department of Economics, Institute for International Economics, Welthandelsplatz 1, 1020, Vienna, Austria, phone: +43 1313364133, fax: +431313 36904141,e-mail: nikolaos.antonakakis@wu.ac.at

${ }^{\dagger}$ University of Portsmouth, Economics and Finance Subject Group, Portsmouth Business School, Portland Street, Portsmouth, PO1 3DE, United Kingdom, phone: ++44 (0)2392844261, fax: ++44 (0)2392844037, email: nikolaos.antonakakis@port.ac.uk

${ }^{\ddagger}$ Vienna University of Economics and Business, Department of Economics, Institute for International Economics, Welthandelsplatz 1, 1020, Vienna, Austria, phone: 433 1313364138, fax: +43131336904138 , e-mail: harald.badinger@wu.ac.at

${ }^{\S}$ Austrian Institute of Economic Research (WIFO), Arsenal, Objekt 20, A-1030, Vienna, Austria, phone: +43 17982601318,e-mail: harald.badinger@wifo.ac.at 


\section{Introduction}

In an increasingly integrated world economy, assessing the international propagation of shocks has become of major interest to the analysis of international economic cycles. In light of the recent economic developments it has also become a major concern, given that the effects of the global financial and European debt crises are still contagiously rippling through the global economy. The present paper provides a quantitative assessment of the evolution and the importance of international propagation mechanisms since the late 19-th century, thereby providing a measure of de-facto integration of the world economy.

Starting from the seminal work by Stock and Watson (2005), a large number of studies has considered the synchronization of business cycles over time and the importance of international, national, and regional factors in shaping business cycle movements, using alternative methods such as (factor) structural VARs, dynamic (latent) factor models, dynamic correlations and concordance correlations (see, e.g., Cerqueira, 2013; Badinger, 2013; Kose et al., 2012; Antonakakis, 2012a; Artis et al., 2011; Crucini et al., 2011; Kose et al., 2008, 2003a,b; Bordo and Helbling, 2003 , to mention a few).

For instance, Kose et al. (2012) employ a dynamic factor model to analyze the evolution of the degree of global cyclical interdependence on annual data for 106 countries over the period 1960-2008. The authors find that during 1985-2008, there has been some convergence of business cycle fluctuations among industrial economies and among emerging economies; at the same time, there has been a concomitant decline in the relative importance of the global factor. Overall they establish evidence on business cycle convergence within each of these two groups of countries but divergence (or decoupling) between them.

Artis et al. (2011) employ a factor structural VAR (FSVAR) to examine BCS across 25 advanced and emerging economies using annual data on real GDP per capita between 1880 and 2006. They identify a secular increase in international business cycle synchronization within a group of European and a group of English-speaking economies that started during 1950-1973 and accelerated since 1973. In other world regions, however, country-specific shocks are still the dominant forces of business cycle dynamics.

Antonakakis (2012a) uses dynamic conditional correlations on annual real per capita GDP data between 1870 and 2011 to examine BCS during US recessions in the G7, and finds that business cycle co-movements significantly increased only for US recessions after the breakdown of the Bretton Woods system of fixed exchange rates and peaked during the Great Recession of 
2007-2009.

Badinger (2013) using spatial econometric techniques based on annual data of real per capita GDP volatility of 135 countries between 1955 and 2006, finds that the world has become significantly smaller in terms of economic distance over the last decades. Spillovers have substantially increased in the post-war period and up to the mid-1980s, followed by a relatively short-lived decline during the Great Moderation period and a second round of increase since the beginning of the 21 st century.

Despite the plethora of studies on business cycle synchronization, there is only a limited amount of studies focusing on shocks to and spillovers among the cyclical component of output growth. The present paper contributes to this strand of the literature in focusing on business cycle spillovers over time and by using an alternative method, namely the VAR-based spillover index introduced by Diebold and Yilmaz (2009, 2012), which has attracted significant attention by both the economics and finance literature (see, inter alia, McMillan and Speight, 2010; Yilmaz, 2010; Bubák et al., 2011; Antonakakis, 2012b; Zhou et al., 2012; Antonakakis and Vergos, 2013) but has rarely been used in the literature on business cycle spillovers so far. Exceptions are Yilmaz (2009), who considers spillover indices among growth rates of industrial production of a sample of the G7 countries using monthly data over the period (1958M1-2009M5) and Antonakakis and Badinger (2012), who consider the same set of countries for the period 1958M22013M8, thereby focusing on the cross-linkages between output volatility and output growth. In addition, this study considers directional spillovers between the groups of developed and developing countries between 1870 and 2012, and as such, it provides a historical, quantitative bird eye's perspective on the world economy, using a large set of countries and a long time span.

Business cycle shocks may be transmitted across economies via four main channels (Eickmeier, 2007): i) the trade channel, ii) the exchange rate channel, iii) the financial integration channel and iv) the confidence channel. The trade channel is explained on the basis of higher exports in one country as a result of higher demand for imports in another country (see, for instance, Canova and Dellas, 1993; Kose and Yi, 2006). According to the exchange rate channel, positive shocks in foreign economies which result in the depreciation of the local currency could lead to an increase of domestic country's competitiveness and thus to an improvement of the domestic trade balance. On the downside, this depreciation could also result in importing inflation. In terms of the financial integration channel, this can bear both positive and negative spillover effects. Specifically, we maintain that financial markets and business cycles are closely related and thus higher level of integration among financial markets could lead to 
stronger spillover effects among business cycles. This is in line with Claessens et al. (2012) who argue that disturbances in financial markets are associated with bust phases of business cycles. The Great Recession of 2007-2009 is a representative example supporting this argument. Furthermore, financial integration allows for greater capital mobility and in this regard, capital flows from a domestic economy to a foreign economy may very well harm the former and improve output levels in the latter (see, inter alia, Canova and Marrinan, 1998; Imbs, 2004). By contrast, Kalemli-Ozcan et al. (2013) show that higher levels of financial integration lead to a decoupling of business cycles. Finally, the confidence channel reflects the response of domestic agents to potential spillovers deriving from foreign shocks to the local economy. In addition, the strength of the spillover depends on whether agents over- or under-react to (asymmetric) information about foreign shocks (Eickmeier, 2007).

Our results indicate that roughly two-thirds of the forecast error variance across the 27 countries' business cycle shocks come from international spillovers. International business cycle spillovers show an increasing trend since the end of World War II and until the mid-1980s and declined considerably afterwards during the period which was dubbed the Great Moderation. After a period of stabilization around the beginning of the 21st century, international business cycle spillovers increased to unprecedented levels during the Great Recession of 2008-2009. Regarding the direction of spillovers, we find that developed countries are net transmitters of cyclical shocks to developing counties throughout the sample.

The remainder of the paper is organized as follows. Section 2 discusses the application of the spillover index approach and describes the data used. Section 3 presents the empirical findings. Section 4 summarizes the main results and concludes.

\section{$2 \quad$ Data and Methodology}

\section{$2.1 \quad$ Data}

We collect annual data for 27 developed and developing countries for which annual per capita GDP in 1990 US dollars (converted at Geary Khamis PPPs) are available between 1870 and 2012 (143 years), yielding a balanced panel with a total of 3861 observations. Table 1 provides the list of countries used along with the classification as 'developing' or 'developed' according to the United Nations. ${ }^{1}$ The series are obtained from the Total Economy Database of the University

\footnotetext{
${ }^{1}$ This classification referring to the most recent period is used throughout the paper
} 
of Groningen, which updates the database of Maddison (2003). ${ }^{2}$

[Insert Table 1 here]

We define $y_{t}=\left(y_{1, t}, \ldots, y_{27, t}\right)^{\prime}$ as the vector comprising data on the 27 countries' cyclical components of annual per capita GDP in year $t$, defined as deviation of the logged actual from potential output per capita; the latter is obtained as Hodrick-Prescott filtered series of (the logarithm of) the countries' GDP per capita. Following Ravn and Uhlig (2002), the smoothing parameter is set to $6.25 .^{3}$

Fig. 1 and Table 2 illustrate and provide descriptive statistics on the countries' series of the cyclical components of annual per capita GDP.

\section{[Insert Fig. 1 here]}

[Insert Table 2 here]

Business cycles of above-average magnitude can be observed for Austria, France, Germany, Greece, Netherlands, Canada, US, Argentina, Chile, Uruguay, Japan and for New Zealand as the absolute value of the average cyclical components is higher compared with the sample average of 0.021714 over all 27 countries - the largest amplitudes are experienced in wars and/or recession periods. On the other hand, below-average magnitude cycles can be found in Belgium, Denmark, Finland, Italy, Norway, Portugal, Spain, Sweden, Switzerland, UK, Brazil, India, Indonesia, Sri Lanka and in Australia.

All series' distributions are leptokurtic and most of these exhibit significantly negative skewness. The only exception is Indonesia, where a significant positive skewness is observed. The negative (positive) skewness indicates that bust (boom) phases of business cycles have a higher magnitude compared with boom (bust) phases. Finally, all series of the cyclical per capita GDP component are stationary according to the augmented Dicky-Fuller (ADF-)test, which rejects the null hypothesis of a unit root for each series. This motivates the use of a (vector autoregressive) VAR model in levels, which will be introduced in the following section.

\footnotetext{
${ }^{2}$ See http://www. conference-board.org/data/economydatabase/ and http://www . worldeconomics.com/Data/ MadisonHistoricalGDP/Madison $\backslash \% 20$ Historical $\ \% 20$ GDP $\backslash \% 20$ Data.efp.

${ }^{3}$ For robustness, we have cross-checked the results using per capita GDP growth instead of the filtered variables. The findings are qualitatively very similar and thus omitted for the sake of brevity.
} 


\subsection{Empirical Methodology}

Our analysis is based on the spillover index approach introduced by Diebold and Yilmaz (2009, 2012). This model builds on the seminal work on VAR models by Sims (1980) and the notion of variance decompositions. In the present context, it measures international spillovers as share of the forecast error variance of countries' cyclical GDP per capita component that is determined by other other countries. Since spillover effects are defined in relative terms (shares of total forecast error variance), the evolution of the importance of international spillover effects over time can be assessed using rolling-window estimation and illustrated using spillover plots.

Starting point for the analysis is the following $K$-th order, $N$-variable VAR

$$
y_{t}=\sum_{k=1}^{K} \Theta_{k} y_{t-k}+\varepsilon_{t}
$$

where $y_{t}=\left(y_{1 t}, y_{2 t}, \ldots, y_{N t}\right)$ is a vector of endogenous variables, comprising $n=1, \ldots, N(27)$ observations on the countries' cyclical component of GDP per capita for year $t ; \Theta_{k}, k=1, \ldots, K$, are $N \times N$ parameter matrices and $\varepsilon_{t} \sim(0, \Sigma)$ is vector of disturbances that are assumed to be independently (though not necessarily identically) distributed over time; $t$ is the year index, ranging from 1 to 143 (1870 to 2012).

Key to the dynamics of the system is the moving average representation of model (1), which is given by $y_{t}=\sum_{p=0}^{\infty} A_{p} \varepsilon_{t-p}$, where the $N \times N$ coefficient matrices $A_{p}$ are recursively defined as $A_{p}=\Theta_{1} A_{p-1}+\Theta_{2} A_{p-2}+\ldots+\Theta_{p} A_{p-l}$, where $A_{0}$ is the $N \times N$ identity matrix and $A_{p}=0$ for $p<0$.

Given that any particular ordering of the variables in our VAR model (that covers 27 countries and a time period of almost 140 years) is hard to justify, we use the variant of the spillover index in Diebold and Yilmaz (2012), which is based on the generalized vector autoregressive framework (Koop et al., 1996; Pesaran and Shin, 1998), in which forecast-error variance decompositions are invariant to the ordering of the variables. Of course, this has advantages and drawbacks. Given our goal to assess the magnitude of international spillovers (as determinants of (the share of) countries' forecast error variances) rather than identifying the causal effects of structural shocks, this appears to be the preferred choice in the present context. ${ }^{4}$

In the generalized vector autoregressive framework, the $H$-step-ahead forecast error variance

\footnotetext{
${ }^{4}$ However, we explore the robustness of our results by using Cholesky factorization with alternative orderings of the variables, as discussed below, and our results remain very similar.
} 
decomposition is

$$
\phi_{i j}(H)=\frac{\sigma_{j j}^{-1} \sum_{h=0}^{H-1}\left(e_{i}^{\prime} A_{h} \Sigma e_{j}\right)^{2}}{\sum_{h=0}^{H-1}\left(e_{i}^{\prime} A_{h} \Sigma A_{h}^{\prime} e_{i}\right)},
$$

where $\Sigma$ is the (estimated) variance matrix of the error vector $\varepsilon, \sigma_{j j}$ the (estimated) standard deviation of the error term for (the cyclical component of per capita GDP of) country $j$, and $e_{i}$ a selection vector with one as the $i$-th element and zeros otherwise. This yields a $27 \times 27$ matrix $\phi(H)=\left[\phi_{i j}(H)\right]_{i, j=1, \ldots 27}$, where each entry gives the contribution of country $j$ to the forecast error variance of country $i$ 's cyclical GDP per capita component. The main diagonal elements contains the (own) contributions of shocks to country $i$ to its own forecast error variance, the off-diagonal elements represent international spillovers, defined here as contributions of other countries $j$ to the forecast error variance of country $i$.

Since the own and cross-variable variance contribution shares do not sum to one under the generalized decomposition, i.e., $\sum_{j=1}^{N} \phi_{i j}(H) \neq 1$, each entry of the variance decomposition matrix is normalized by its row sum, such that

$$
\tilde{\phi}_{i j}(H)=\frac{\phi_{i j}(H)}{\sum_{j=1}^{N} \phi_{i j}(H)}
$$

with $\sum_{j=1}^{N} \tilde{\phi}_{i j}(H)=1$ and $\sum_{i, j=1}^{N} \tilde{\phi}_{i j}(H)=N$ by construction.

This ultimately allows to define a total spillover index, which is given by

$$
T S(H)=\frac{\sum_{i, j=1, i \neq j}^{N} \tilde{\phi}_{i j}(H)}{\sum_{i, j=1}^{N} \tilde{\phi}_{i j}(H)} \times 100=\frac{\sum_{i, j=1, i \neq j}^{N} \tilde{\phi}_{i j}(H)}{N} \times 100
$$

which measures, on average over all countries, the contribution of spillovers from shocks to all (other) countries to the total forecast error variance.

This approach is quite flexible and allows to obtain a more differentiated picture by considering directional spillovers: Specifically, the directional spillovers received by country $i$ from all other country $j$ are defined as

$$
D S_{i \leftarrow j}(H)=\frac{\sum_{j=1, j \neq i}^{N} \tilde{\phi}_{i j}(H)}{\sum_{i, j=1}^{N} \tilde{\phi}_{i j}(H)} \times 100=\frac{\sum_{j=1, j \neq i}^{N} \tilde{\phi}_{i j}(H)}{N} \times 100
$$

and the directional spillovers transmitted by country $i$ to all other countries $j$ as

$$
D S_{i \rightarrow j}(H)=\frac{\sum_{j=1, j \neq i}^{N} \tilde{\phi}_{j i}(N)}{\sum_{i, j=1}^{N} \tilde{\phi}_{j i}(H)} \times 100=\frac{\sum_{j=1, j \neq i}^{N} \tilde{\phi}_{j i}(H)}{N} \times 100 .
$$

Notice that the set of directional spillovers provides a decomposition of total spillovers into those coming from (or to) a particular country. 
By subtracting Equation (5) from Equation (6) the net spillovers from country $i$ to all other countries $j$ are obtained as

$$
N S_{i}(H)=D S_{i \rightarrow j}(H)-D S_{i \leftarrow j}(H),
$$

providing information on whether a country is a receiver or transmitter of shocks in net terms. Put differently, Equation (7) provides summary information about how much each country contributes to the business cycles in other countries, in net terms.

\section{Empirical Findings}

In the following we present the results from our empirical analysis. We start with the estimates of the spillover index for the full sample period and then consider the time-varying nature of spillovers using rolling window estimation.

\subsection{Spillover Indices}

Table 3 presents the estimation results for the spillover indices defined in in Equations (4)-(7), based on 4-year ahead forecast error variance decompositions. Before discussing the results, let us first describe the structure and elements of Table 3 . The $i j-$ th entry is the estimated contribution to the forecast error variance of variable $i$ coming from shocks (innovations) to variable $j$ (see Equation (2)). Note that each variable is associated with one of the countries' cyclical component of per capita GDP. Hence, the diagonal elements $(i=j)$ measure domestic spillovers of business cycle shocks (over time), while the off-diagonal elements $(i \neq j)$ capture international, i.e., cross-country spillovers of business cycle shocks.

In addition, the row sums excluding the main diagonal elements (labeled 'Directional from others', see Equation (5)) report the total spillovers to (received by) the particular country in the respective row, whereas the column sums (labeled 'Directional to others', see Equation (6)) report the total spillovers from (transmitted by) the particular country in the respective column. The difference between each country's (off-diagonal) column sum and the same country's row sum gives the net spillovers of the respective country to all other countries (see Equation (7)). Finally, the total spillover index defined in Equation (4), is given in the lower right corner of Table 3, is approximately equal to the grand off-diagonal column sum (or row sum) relative to the grand column sum including diagonals (or row sum including diagonals), expressed in 
percentage points. ${ }^{5}$

[Insert Table 3 here]

Several interesting results emerge from Table 3, which summarizes the average spillovers for the full sample period from 1870-2012. First, own-country business cycle spillovers explain the highest share of forecast error variance, as the diagonal elements receive higher values compared with the off-diagonal elements. For instance, innovations to business cycles in the United States explain $22.5 \%$ of the 4 -year forecast error variance of business cycles in the United States, but only $11.7 \%$ in Canada and $5.8 \%$ in Chile.

Second, the most important transmitters of business cycle shocks are the Netherlands followed by the United Kingdom, Japan and Switzerland, while New Zealand, Sri Lanka, Germany and Indonesia are the most important receivers of business cycles shocks. These results are supported by the estimated net directional spillovers reported in the last row of Table 3 .

Moreover, these results indicate that half of the developed countries $(50 \%, 10$ out of 20$)$ are net transmitters of business cycles shocks, while most developing countries (86\%, 6 out of 7 ) are net receivers of business cycles shocks. Put differently, business shocks in developed countries have historically been the dominant sources of international spillovers.

Third, and most importantly, according to the total spillover index reported at the lower right corner of Table 3, which effectively distils the various directional spillovers into one single index, on average, $65 \%$ of the forecast error variance in international business cycles comes from spillovers of shocks across countries.

In summary, the results reported in Table 3 suggest that, on average, both the total and directional spillovers of international business cycles were historically extremely high during our sample period, highlighting the strong role of business cycle interdependencies. ${ }^{6}$

\subsection{Spillover Plots}

While the average results for the full sample period in Table 3 are indicative they might mask interesting changes in the pattern of spillovers, given the long time span of 143 years considered. Hence, we estimate the model in Equation (1) using 60-year rolling windows and calculate the

\footnotetext{
${ }^{5}$ The approximate nature of the result is due to the fact that the contributions of the variables do not sum to one under the generalized decomposition framework and have to be normalized (see Equation (3)).

${ }^{6}$ We have explored the robustness of our results using alternative forecasting horizons (i.e. 8 and 12 years) and the results remain qualitatively similar.
} 
variance decompositions and spillover indices for each of 83 subperiods. ${ }^{7}$ As a result, we obtain time-varying estimates of spillover indices, allowing us to assess the intertemporal evolution of total and directional business cycle spillovers within and between advanced and developing countries.

\section{[Insert Fig. 2 here]}

Fig. 2 presents the results for the time-varying total spillover index obtained from the 60year rolling windows estimation. According to this figure we observe a large variation in the total spillover index, which turns out very responsive to extreme economic events such as wars (and periods of rising protectionism or integration) and U.S. recessions. For instance, the total spillover index peaks during World War II, in the mid-1980s and during the Great Recession of 2007-2009. Furthermore, there is an increasing trend since the end of World War II and until the mid-1980s. After that, international business cycle interdependencies declined during the period that was dubbed the Great Moderation, and stabilized around the beginning of the 21st century. During the Great Recession of 2008-2009, international business cycle spillovers increased to an all-time high. This suggests that interdependencies across countries tend to increase significantly during economic downturns (and wars), a finding which is in line with previous studies (Imbs, 2010; Yetman, 2011; Antonakakis, 2012a; Badinger, 2013).

In addition, these results are in line with previous studies highlighting the role of international (economic and financial) spillovers as a crucial determinant of countries' business cycle innovations. For instance, Carare and Mody (2012), who use factor-structural vector autoregressive models for a sample of 22 countries between 1960 and 2007, find that 50\%-75\% of total volatility in the post-1995 period is due to international spillovers.

Despite results for the total spillover index being informative, they might discard directional information that is contained in the "Directional to others" row (Equation (5)) and the "Directional from others" column (Equation (6)) in Table 3. Fig. 3 presents the estimated 60-year rolling windows directional spillovers from each of the countries (business cycles) to others (corresponding to the "Directional to others" row in Table 3), while Fig. 4 presents the estimated 60 -year rolling windows directional spillovers from other countries to each (corresponding to the "Directional from others" column in Table 3).

[Insert Fig. 3 here]

\footnotetext{
${ }^{7}$ Our results reported below remain robust to alternative choices of window length (i.e. 20,40 and 80 years).
} 
[Insert Fig. 4 here]

According to these two figures, directional spillovers from or to each business cycle range between $2 \%-6 \%$ (on average per country) and are of bidirectional nature. Nevertheless, they behave rather heterogeneously over time and follow a similar pattern as the one found for the total spillover index. That is, directional spillovers from or to each business cycle generally peak during the World War II, in the mid-1980s and during the Great Recession of 2007-2009. In addition, there is a clear increasing trend since the end of World War II and until the mid-1980s. After that, directional business cycle spillovers exhibit a short-lived decline during the Great Moderation, and a second round of increase since the beginning of the 21st century. The pattern of these results are in line with the findings of Badinger (2013) for volatility spillovers.

A similar picture emerges when looking at the net directional spillover indices obtained from the 60 -year rolling window estimation. According to Fig. 5, which plots the time-varying net directional spillovers, we see that Belgium, France, Italy, Netherlands, Norway, Spain, Switzerland, UK, Canada, Japan and Australia are mostly net transmitters of business cycles shocks during our sample period, while Denmark, Finland, Germany, Portugal, Argentina, Brazil, Chile, Uruguay, India, Indonesia, Sri Lanka and New Zealand are mainly at the receiving ends of net business cycle transmissions. The picture is not clear for Austria, Greece, Sweden and the United States. Nevertheless, the United States show up to be a net receiver between the 40s and the beginning of the $90 \mathrm{~s}$, while a net transmitter before the $30 \mathrm{~s}$ and since the $90 \mathrm{~s}$. The latter periods coincide with the Great Depression of 1930 and the latest three recessions (in 1990-1991, 2001 and 2007-2009) in the United States indicating the prevalence of spillovers from the United States during downturns in economic activity.

\section{[Insert Fig. 5 here]}

A similar picture is observed in Greece. Greece has become a significant net transmitter during the period just before the introduction of the Euro (possibly due the uncertainty surrounding the country's non compliance with the convergence criteria laid out in the Maastricht Treaty) and remains a net transmitter until the end of the sample period that includes the Eurozone debt crisis.

Our findings emphasize that - in a highly integrated world economy - it is not only the large players that matter; also shocks to small countries can have large, destabilizing effects on the world economy. 


\subsection{Net Spillovers Between Developed and Developing countries}

To examine further the net spillover effects across global economies, we turn our attention to net spillover effects among groups of countries, namely developed countries and developing countries. Fig. 6 illustrates these net spillovers among the two groups.

\section{[Insert Fig. 6 here]}

It is clear from this figure that developed countries are historically the dominant net transmitters of business cycle shocks to developing countries. The net spillover index ranges between $1 \%$ and $9 \%$ overtime, and reaches a peak during the World War II and the Great Recession. In these two periods, net spillovers of business cycles shocks from developed to developing countries were more pronounced and received their highest values.

\subsection{Robustness analysis}

In an attempt to check the robustness of the results obtained based on the generalised version of the spillover index by Diebold and Yilmaz (2012), we also employ the spillover index approach of Diebold and Yilmaz (2009), which is based on the Cholesky decomposition and in which the forecast error variance decomposition is sensitive to the ordering of the variables in the VAR. In particular, we analyse 100 random permutations (different orderings of the variables in the VAR) and construct the corresponding spillover indices for each ordering. Figure 7 presents the minimum and maximum values that the total spillover index receives based on Cholesky factorization. According to this figure, the results are in line with those of our main approach reported in Figure 2. In particular, the spillover index varies between $75 \%$ and $90 \%$ and peaks during extreme economic events such as wars, periods of rising protectionism/integration, and U.S. recessions. Moreover, spillovers follow an increasing trend since the end of World War II till the 1980s. Afterwards, international business cycle spillovers follow a declining trend during the Great Moderation until the mid-1990s, when the trend reverses back to positive. Finally, spillovers reach unprecedented heights during the Great Recession of 2008-2009. The similarity of the pattern obtained using these two alternative approaches is reassuring and underlines the robustness of the results.

[Insert Fig. 7 here] 


\section{Conclusions}

This paper considers the magnitude, importance and evolution of international business cycle interdependencies, using annual data on per capita GDP for a sample of 27 developed and developing countries over the period 1870-2012. Methodologically, we employ the VAR-based spillover index by Diebold and Yilmaz (2012), which is well suited for the investigation of international business cycle spillovers but has rarely been used in this strand of the literature so far.

We find that the transmission of international shocks is an important source of business cycle fluctuations. On average over the whole sample period, $65 \%$ of forecast error variance across the 27 countries' business cycle is due to international spillovers. Moreover, international business cycle spillovers show a large variation over time. The importance of spillovers increased considerably after World War II and until the mid-1980s, followed by a declining trend during the period of the Great Moderation. Spillovers then remained relatively stable around the beginning of the 21st century and reached an all-time high during the Great Recession of 20082009. Regarding the direction of spillovers, developed countries are consistently ranked as net transmitters of cyclical shocks to developing countries.

Our findings also suggest that it is not only the group of the largest economies that matter. Even shocks to small economies (such as the Netherlands, or more recently Greece) can trigger substantional international spillovers. Moreover, the concurrence of the recent surge in international spillovers with the increase in financial openness and capital mobility places the analysis of the linkages between the real and financial sectors of the global economy at the forefront of the macroeconomic research agenda. Hence, the identification of the magnitude of spillovers between the real and financial economy and their transmission channels are important questions that remain to be addressed in future research.

As the analysis of the present study has focused solely on the business cycles transmission mechanism, a straightforward avenue of future research, is to extend the analysis by incorporating additional channels, such as the financial sector, trade and the uncertainty channel.

At a more general level, our findings have an important policy implication. As the recent financial and economic crisis has shown, common shocks rapidly spread over the globe and have a magnified impact. The large magnitude of spillover effects obtained in the present study underlines the importance of establishing macroprudential stabilization policies. At the same time, they point to potentially large gains from international policy coordination or supranational 
policies.

\section{Acknowledgements}

The authors like to thank the editor (Mark Taylor) and two anonymous reviewers for helpful comments on a previous version of this paper. The usual disclaimer applies.

\section{References}

Antonakakis, N., 2012a. Business Cycle Synchronization During US Recessions Since the Beginning of the 1870s. Economics Letters 117 (2), 467-472.

Antonakakis, N., 2012b. Exchange Return Co-movements and Volatility Spillovers Before and After the Introduction of Euro. Journal of International Financial Markets, Institutions and Money 22 (5), 1091-1109.

Antonakakis, N., Badinger, H., May 2012. Output Volatility, Economic Growth, and CrossCountry Spillovers: New Evidence for the G7 Countries. Department of Economics Working Papers wuwp141, Vienna University of Economics, Department of Economics.

Antonakakis, N., Vergos, K., 2013. Sovereign Bond Yield Spillovers in the Euro Zone During the Financial and Debt Crisis. Journal of International Financial Markets, Institutions and Money 26, $258-272$.

Artis, M., Chouliarakis, G., Harischandra, P. K. G., 03 2011. Business Cycle Synchronization Since 1880. Manchester School 79 (2), 173-207.

Badinger, H., 2013. Measuring the World Economy. The World Economy 36 (1), 12-30.

Bordo, M. D., Helbling, T., Dec 2003. Have National Business Cycles Become More Synchronized? NBER Working Papers 10130, National Bureau of Economic Research, Inc.

Bubák, V., Kocenda, E., Zikes, F., 2011. Volatility Transmission in Emerging European Foreign Exchange Markets. Journal of Banking 85 Finance 35 (11), 2829-2841.

Canova, F., Dellas, H., 1993. Trade interdependence and the international business cycle. Journal of International Economics 34 (1-2), 23-47. 
Canova, F., Marrinan, J., 1998. Sources and propagation of international output cycles: Common shocks or transmission? Journal of International Economics 46 (1), 133-166.

Carare, A., Mody, A., 2012. Spillovers of Domestic Shocks: Will They Counteract the "Great Moderation"? International Finance 15 (1), 69-97.

Cerqueira, P., 2013. A Closer Look at the World Business Cycle Synchronization. International Economics and Economic Policy 10 (3), 349-363.

Claessens, S., Kose, M. A., Terrones, M. E., 2012. How do business and financial cycles interact? Journal of International economics 87 (1), 178-190.

Crucini, M., Kose, A., Otrok, C., 2011. What are the Driving Forces of International Business Cycles? Review of Economic Dynamics 14 (1), 156-175.

Diebold, F. X., Yilmaz, K., 2009. Measuring Financial Asset Return and Volatility Spillovers, with Application to Global Equity Markets. Economic Journal 119 (534), 158-171.

Diebold, F. X., Yilmaz, K., 2012. Better to Give than to Receive: Predictive Directional Measurement of Volatility Spillovers. International Journal of Forecasting 28 (1), 57-66.

Eickmeier, S., 2007. Business cycle transmission from the US to Germany - A structural factor approach. European Economic Review 51 (3), 521-551.

Imbs, J., 2004. Trade, finance, specialization, and synchronization. The Review of Economics and Statistics 86 (3), 723-734.

Imbs, J., 2010. The First Global Recession in Decades. IMF Economic Review 58 (2), 327-354.

Kalemli-Ozcan, S., Papaioannou, E., Peydró, J.-L., 2013. Financial Regulation, Financial Globalization, and the Synchronization of Economic Activity. Journal of Finance 68 (3), 11791228.

Koop, G., Pesaran, M. H., Potter, S. M., 1996. Impulse Response Analysis in Nonlinear Multivariate Models. Journal of Econometrics 74 (1), 119-147.

Kose, M. A., Otrok, C., Prasad, E., 2012. Global Business Cycles: Convergence or Decoupling? International Economic Review 53 (2), 511-538.

Kose, M. A., Otrok, C., Whiteman, C. H., 2003a. International Business Cycles: World, Region, and Country-Specific Factors. American Economic Review 93 (4), 1216-1239. 
Kose, M. A., Otrok, C., Whiteman, C. H., 2008. Understanding the Evolution of World Business Cycles. Journal of International Economics 75 (1), 110-130.

Kose, M. A., Prasad, E. S., Terrones, M. E., 2003b. How Does Globalization Affect the Synchronization of Business Cycles? American Economic Review 93 (2), 57-62.

Kose, M. A., Yi, K.-M., 2006. Can the standard international business cycle model explain the relation between trade and comovement? Journal of International Economics 68 (2), 267-295.

Maddison, A., 2003. The World Economy: Historical Statistics. Paris, Organization of Economic Cooperation and Development.

McMillan, D. G., Speight, A. E., 2010. Return and volatility Spillovers in Three Euro Exchange Rates. Journal of Economics and Business 62 (2), 79-93.

Pesaran, H. H., Shin, Y., 1998. Generalized Impulse Response Analysis in Linear Multivariate Models. Economics Letters 58 (1), 17-29.

Ravn, M. O., Uhlig, H., 2002. On Adjusting the Hodrick-Prescott Filter for the Frequency of Observations. The Review of Economics and Statistics 84 (2), 371-375.

Sims, C., 1980. Macroeconomics and Reality. Econometrica 48, 1-48.

Stock, J. H., Watson, M. W., 2005. Understanding Changes in International Business Cycle Dynamics. Journal of the European Economic Association 3 (5), 968-1006.

Yetman, J., 2011. Exporting Recessions: International Links and the Business Cycle. Economics Letters 110 (1), 12-14.

Yilmaz, K., 2009. International Business Cycle Spillovers. Koc University-TUSIAD Economic Research Forum Working Papers 0903, Koc University-TUSIAD Economic Research Forum.

Yilmaz, K., 2010. Return and Volatility Spillovers Among the East Asian Equity Markets. Journal of Asian Economics 21 (3), 304-313.

Zhou, X., Zhang, W., Zhang, J., 2012. Volatility Spillovers Between the Chinese and World Equity Markets. Pacific-Basin Finance Journal 20 (2), 247-270. 
Figure 1: Cyclical components of annual per capita GDP based on HP filtering

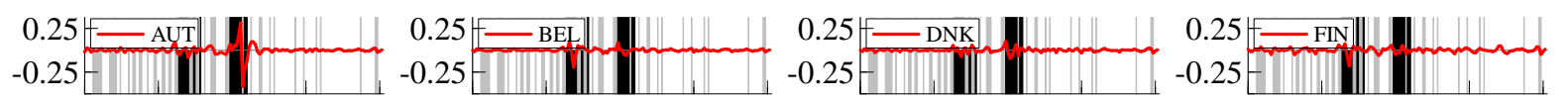

18701905194019752010187019051940197520101870190519401975201018701905194019752010

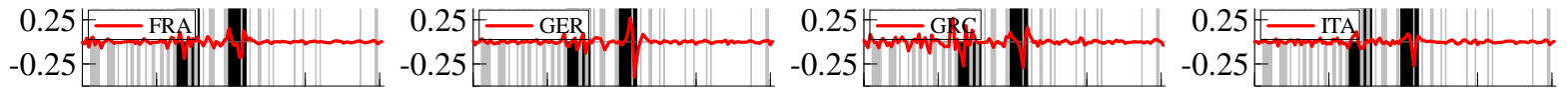

18701905194019752010187019051940197520101870190519401975201018701905194019752010

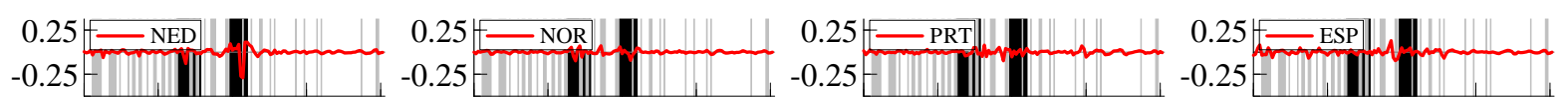

$18701905194019752010 \quad 18701905194019752010 \quad 1870190519401975201018701905194019752010$

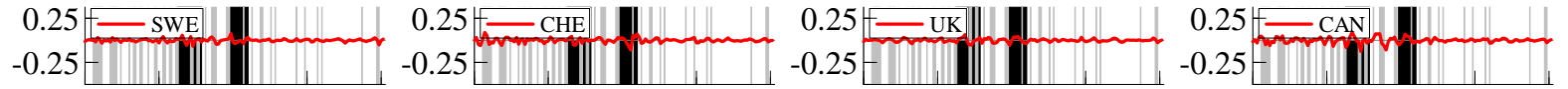

18701905194019752010187019051940197520101870190519401975201018701905194019752010

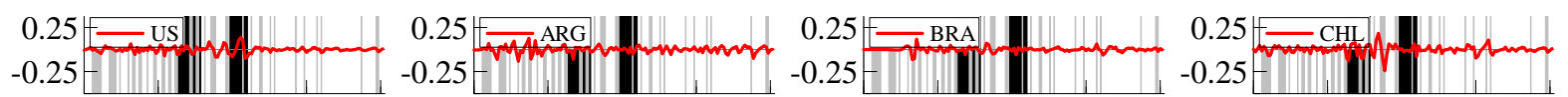

18701905194019752010187019051940197520101870190519401975201018701905194019752010
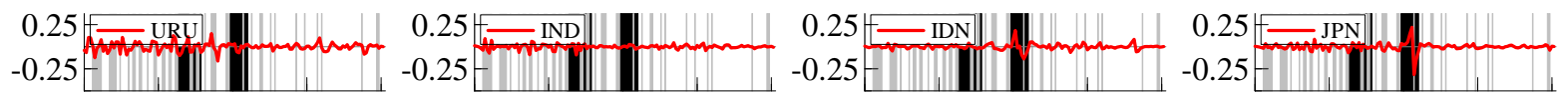

18701905194019752010187019051940197520101870190519401975201018701905194019752010

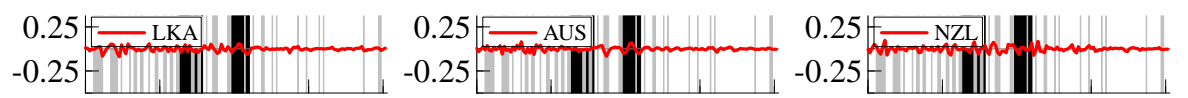

$18701905194019752010 \quad 18701905194019752010 \quad 18701905194019752010$

Notes: Grey shading denotes US recessions as defined by NBER, and black shading world war periods. 
Figure 2: Total spillover index, 1870-2012

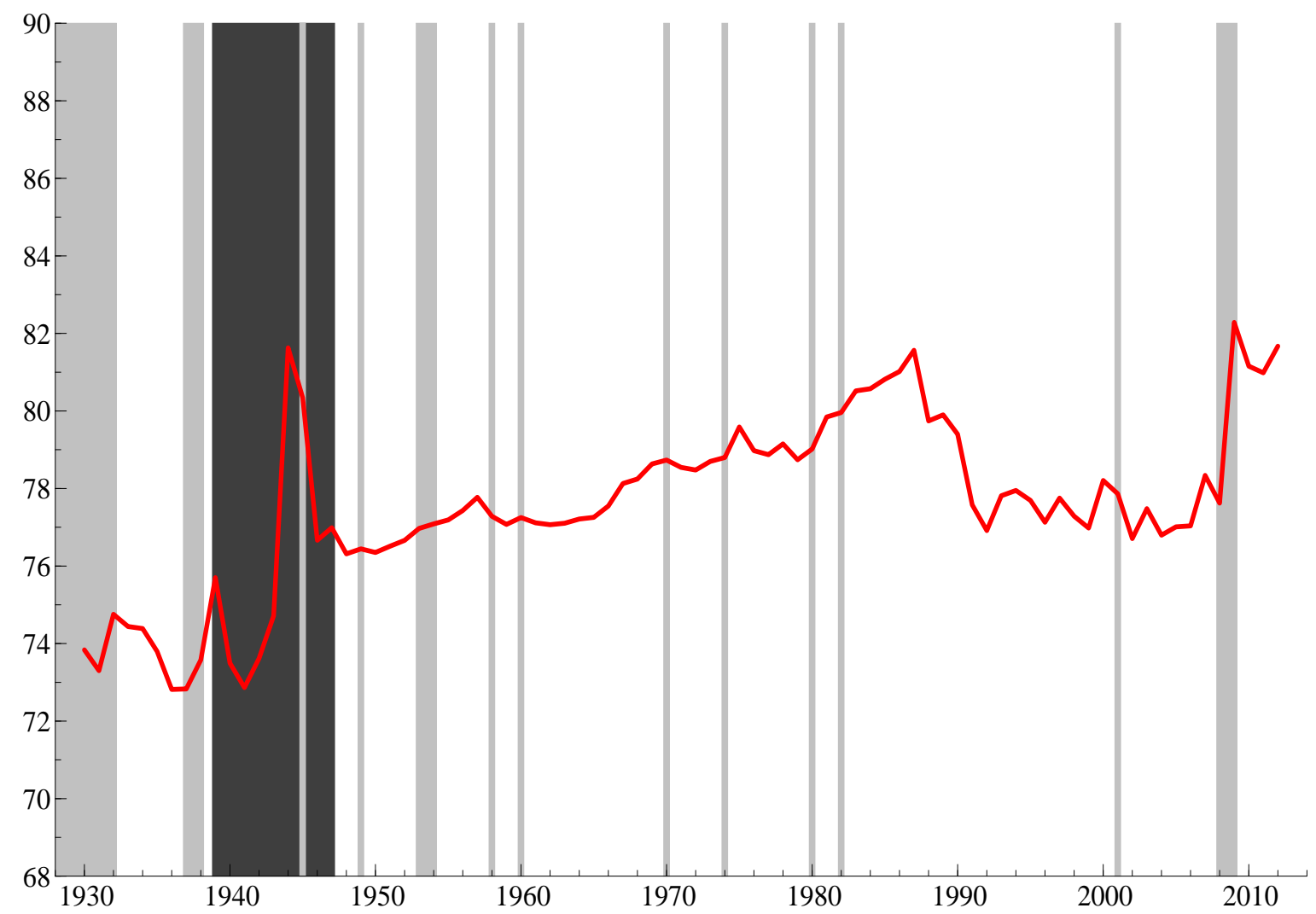

Notes: Plot of moving total spillover index estimated using 60-year rolling windows (and hence starting in 1930). Grey shading denotes US recessions as defined by NBER, and black shading world war periods. 
Figure 3: Directional spillovers from each country's cyclical components of real per capita GDP, $1870-2012$
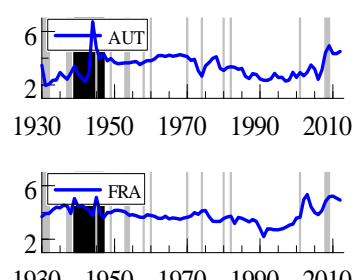

$1930 \quad 1950 \quad 1970 \quad 1990 \quad 2010$

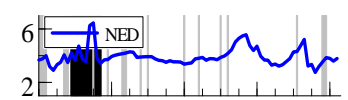

$\begin{array}{lllll}1930 & 1950 & 1970 & 1990 & 2010\end{array}$

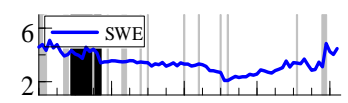

$\begin{array}{lllll}1930 & 1950 & 1970 & 1990 & 2010\end{array}$
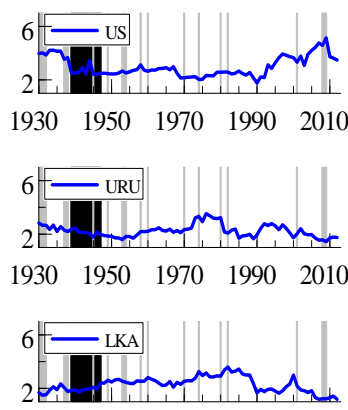

$\begin{array}{lllll}1930 & 1950 & 1970 & 1990 \quad 2010\end{array}$
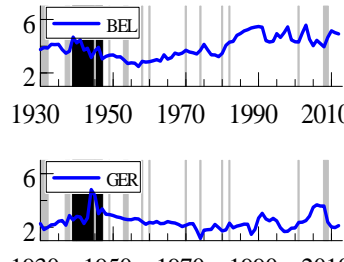

$\begin{array}{lllll}1930 & 1950 & 1970 & 1990 & 2010\end{array}$

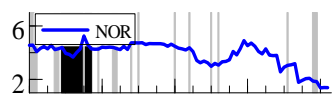

$1930 \quad 1950 \quad 1970 \quad 1990 \quad 2010$

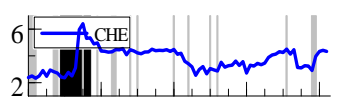

$\begin{array}{lllll}1930 & 1950 & 1970 & 1990 & 2010\end{array}$

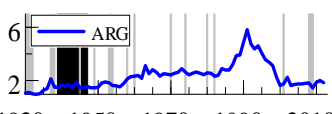

$193019501970 \quad 19902010$

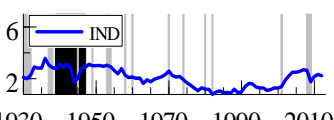

$\begin{array}{lllll}1930 & 1950 & 1970 & 1990 & 2010\end{array}$

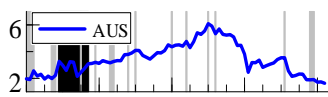

$\begin{array}{lllll}1930 & 1950 & 1970 & 1990 & 2010\end{array}$

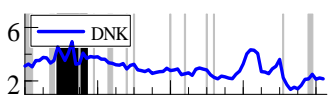

$\begin{array}{lllll}1930 & 1950 & 1970 & 1990 & 2010\end{array}$

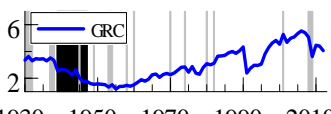

$193019501970 \quad 1990 \quad 2010$

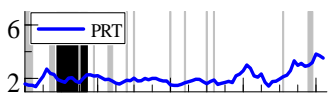

$1930 \quad 1950 \quad 1970 \quad 1990 \quad 2010$

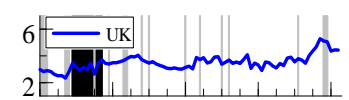

$\begin{array}{lllll}1930 & 1950 & 1970 & 1990 & 2010\end{array}$

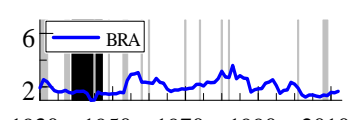

$\begin{array}{lllll}1930 & 1950 & 1970 & 1990 \quad 2010\end{array}$

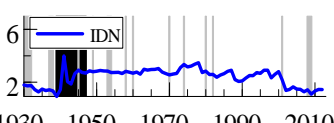

$193019501970 \quad 1990 \quad 2010$

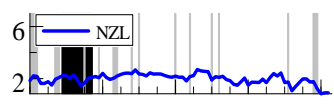

$1930 \quad 1950 \quad 1970 \quad 1990 \quad 2010$
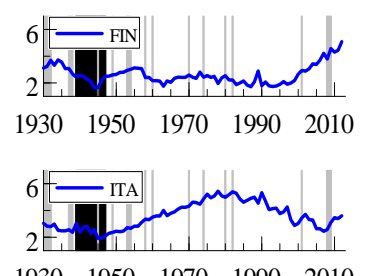

$19301950 \quad 1970 \quad 1990 \quad 2010$

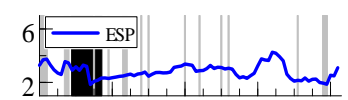

$\begin{array}{lllll}1930 & 1950 & 1970 & 1990 & 2010\end{array}$

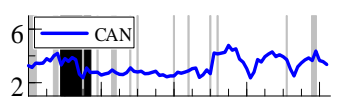

$\begin{array}{lllll}1930 & 1950 & 1970 & 1990 & 2010\end{array}$

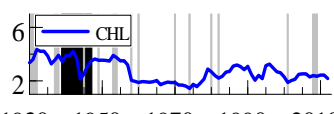

$\begin{array}{lllll}1930 & 1950 & 1970 & 1990 & 2010\end{array}$

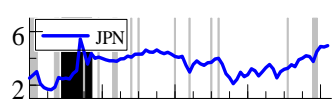

$\begin{array}{lllll}1930 & 1950 & 1970 & 1990 & 2010\end{array}$

Notes: Plots of moving directional spillover indices estimated using 60-year rolling windows. Grey shading denotes US recessions as defined by NBER, and black shading world war periods. 
Figure 4: Directional spillovers to each country's cyclical components of real per capita GDP, $1870-2012$
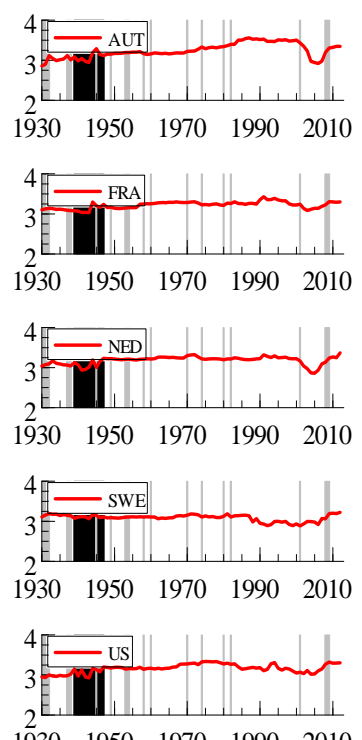

197019902010
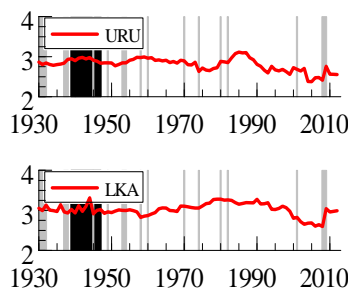
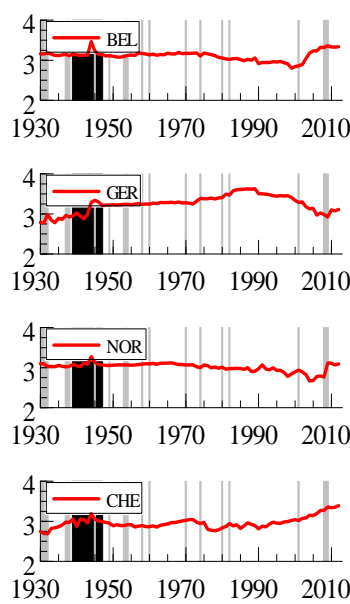

$1930 \quad 1950 \quad 1970 \quad 1990 \quad 2010$
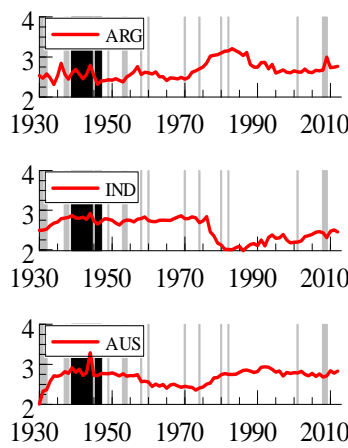
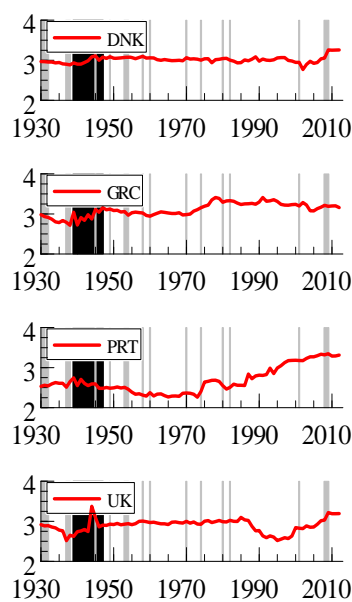

$\begin{array}{lllll}1930 & 1950 & 1970 & 1990 \quad 2010\end{array}$
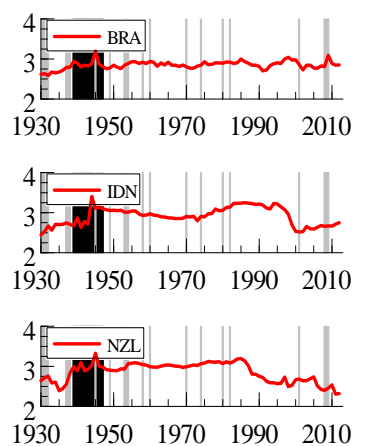
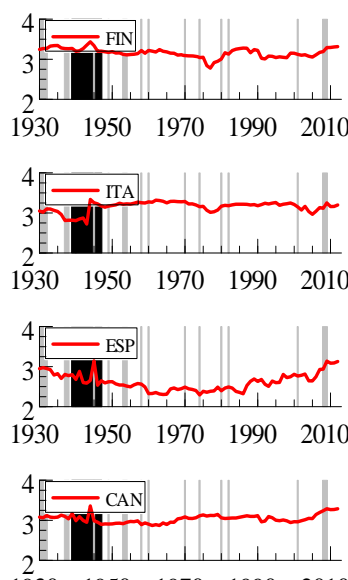

$1930 \quad 19501970 \quad 1990 \quad 2010$
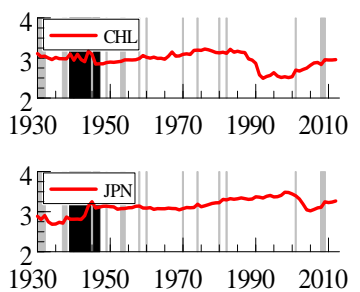

$19301950 \quad 1970 \quad 1990 \quad 2010$

Notes: Plots of moving directional spillover indices estimated using 60-year rolling windows. Grey shading denotes US recessions as defined by NBER, and black shading world war periods. 
Figure 5: Net directional spillovers, 1870-2012
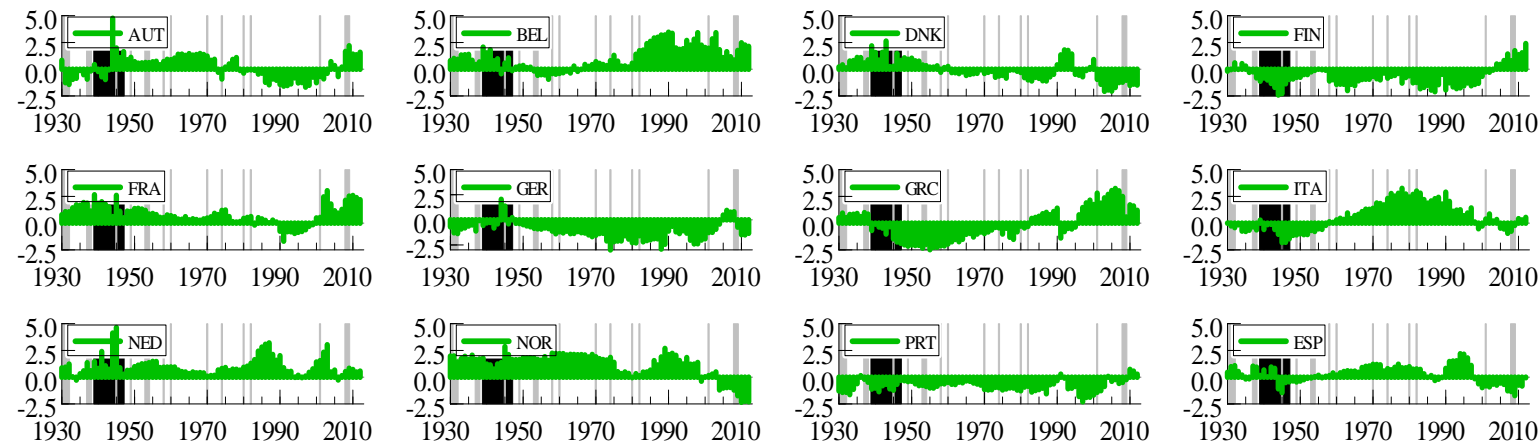

$19301950 \quad 1970 \quad 1990 \quad 2010$

$1930 \quad 1950 \quad 1970 \quad 1990 \quad 2010$

$19301950 \quad 1970 \quad 1990 \quad 2010$
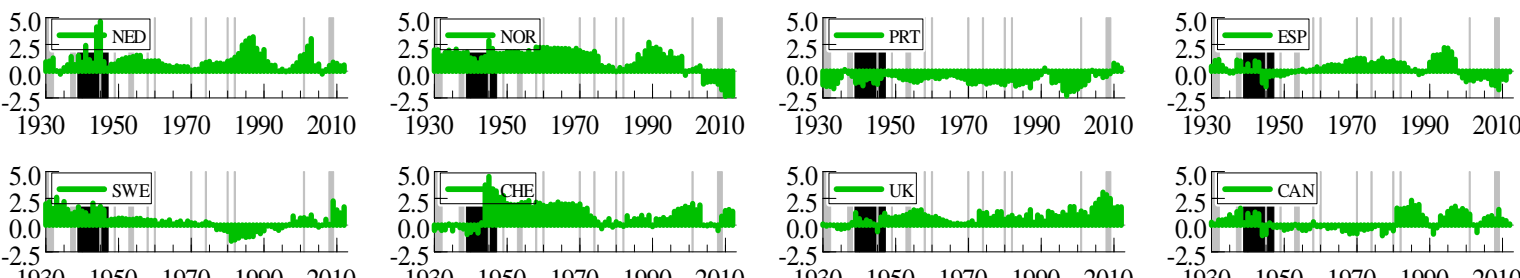

$\begin{array}{lllll}1930 & 1950 & 1970 & 1990 \quad 2010\end{array}$

$\begin{array}{lllll}1930 & 1950 & 1970 & 1990 \quad 2010\end{array}$

$1930 \quad 1950 \quad 1970 \quad 1990 \quad 2010$
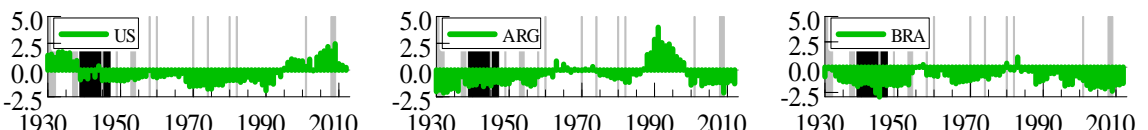

$1930 \quad 1950 \quad 1970 \quad 1990 \quad 2010$
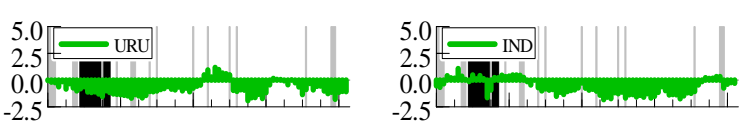

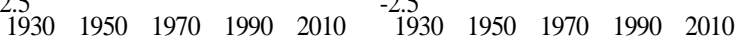
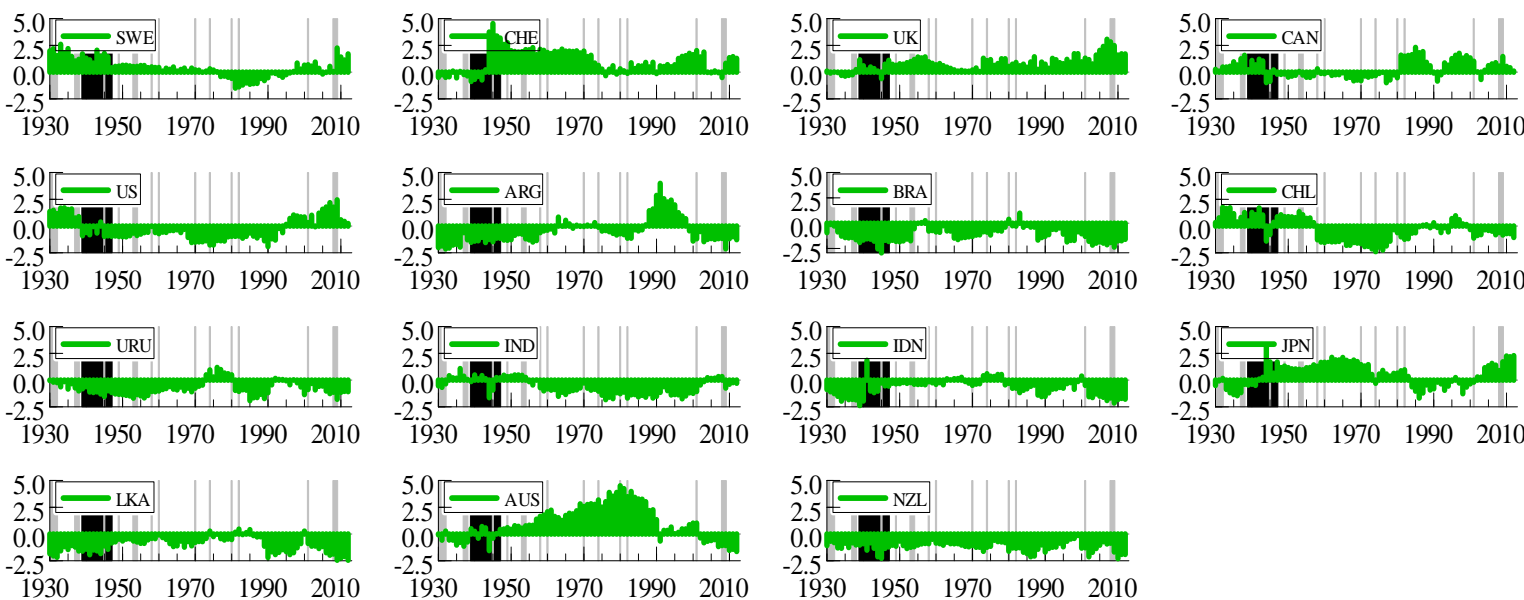

$1930 \quad 1950 \quad 1970 \quad 1990 \quad 2010$
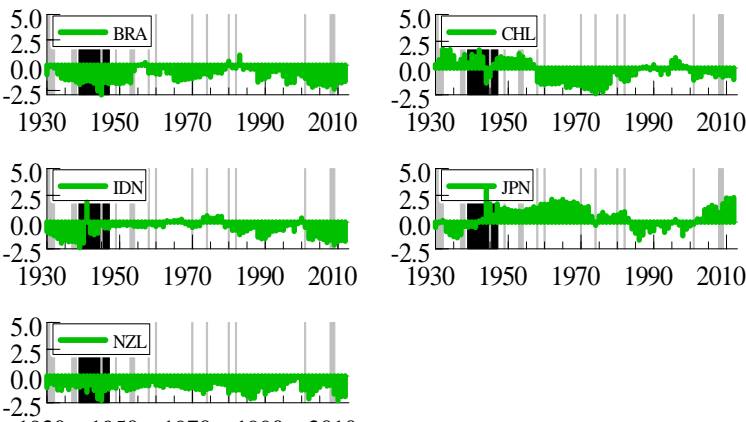

$\begin{array}{rrrrr}-2.5 & 1930 & 1950 & 1970 & 1990 \quad 2010\end{array}$

$\begin{array}{lllll}1930 & 1950 & 1970 & 1990 & 2010\end{array}$

$19301950 \quad 1970 \quad 1990 \quad 2010$

$1930 \quad 1950 \quad 1970 \quad 1990 \quad 2010$

Notes: Plot of moving net directional spillover indices estimated using 60-year rolling windows. Grey shading denotes US recessions as defined by NBER, and black shading world war periods. 
Figure 6: Net directional spillovers, advanced vs developing countries, 1870-2012

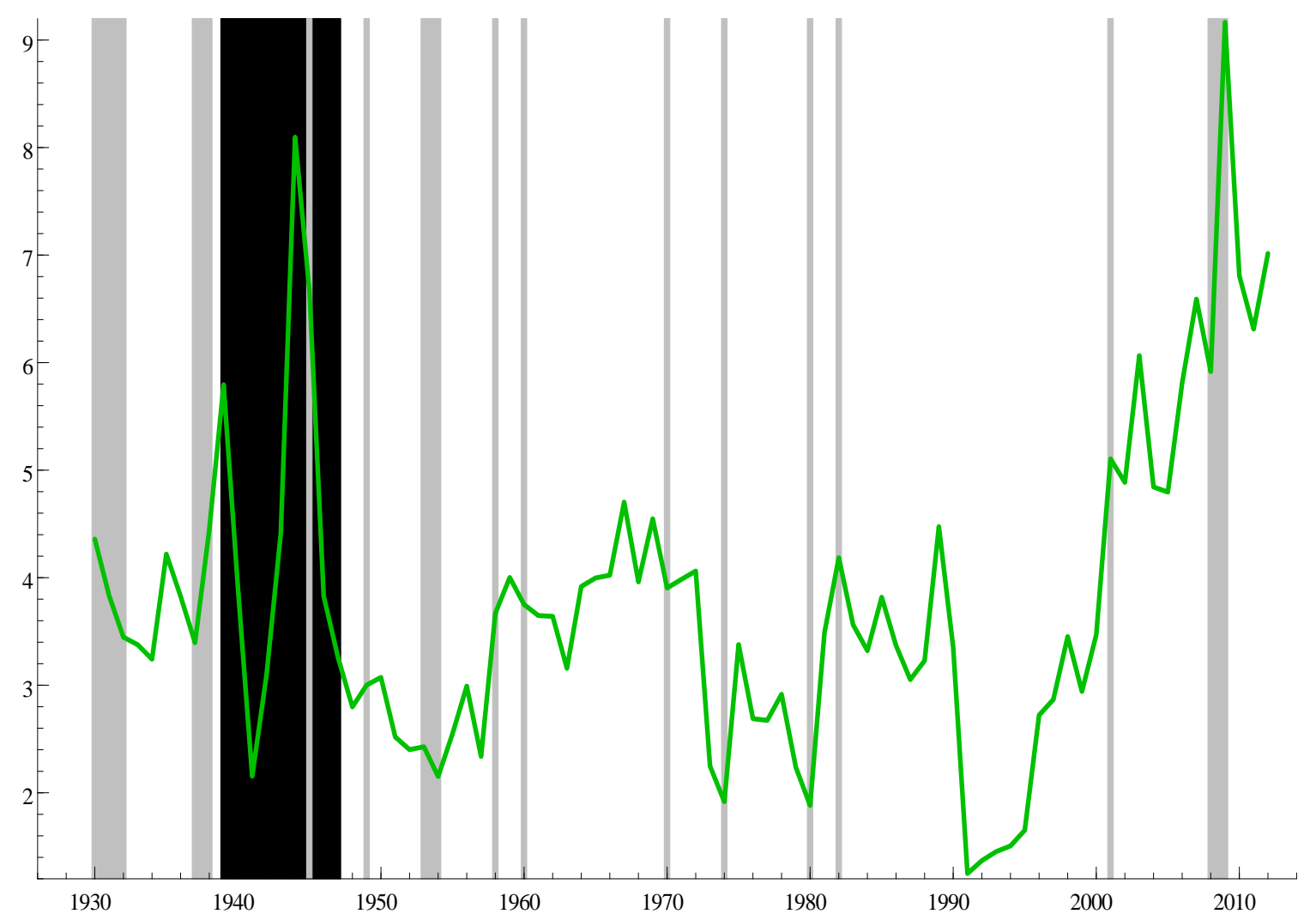

Notes: Plot a moving net directional spillover index estimated using 60-year rolling windows. Grey shading denotes US recessions as defined by NBER, and black shading world war periods. 
Figure 7: Maximum and minimum total spillovers based on Cholesky factorization with random permutations, $1870-2012$

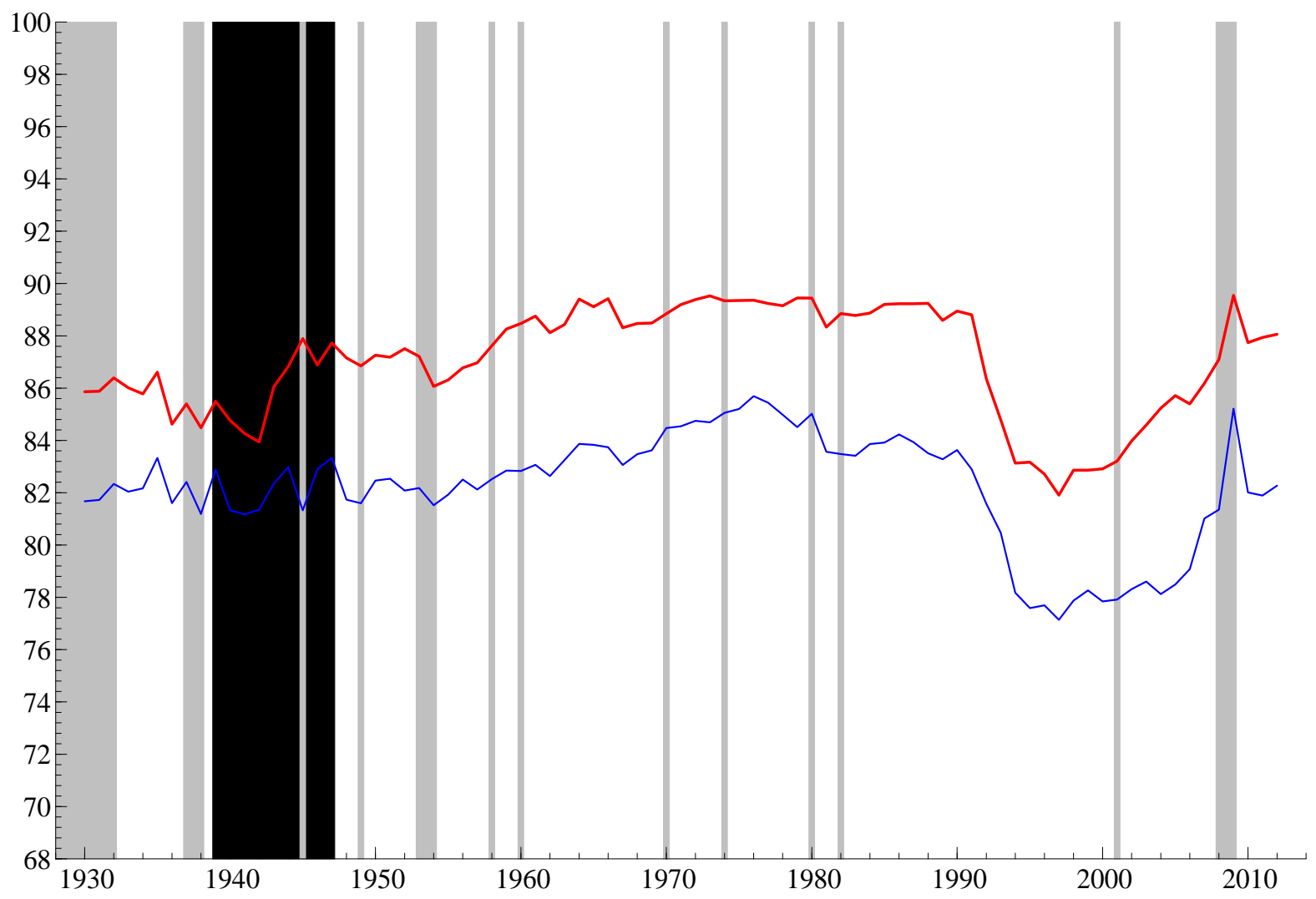

Notes: Plot of maximum and minimum moving total spillover index estimated based on Cholesky factorization with 100 randomly chosen orderings using 60-year rolling windows (and hence starting in 1930). Grey shading denotes US recessions as defined by NBER, and black shading world war periods. 
Table 1: List and Classification of Countries

\begin{tabular}{|c|c|c|c|}
\hline Advanced Countries & Acronym & Developing Countries & Acronym \\
\hline \multicolumn{2}{|c|}{ Western European Countries } & \multicolumn{2}{|c|}{ Latin American Countries } \\
\hline Austria & AUT & Argentina & $\mathrm{ARG}$ \\
\hline Belgium & BEL & Brazil & BRA \\
\hline Denmark & DNK & Chile & CHL \\
\hline Finland & FIN & Uruguay & URU \\
\hline France & FRA & \multicolumn{2}{|c|}{ East Asian Countries } \\
\hline Germany & GER & India & IND \\
\hline Greece & GRC & Indonesia & IDN \\
\hline Italy & ITA & Sri Lanka & LKA \\
\hline Netherlands & NED & & \\
\hline Norway & NOR & & \\
\hline Portugal & PRT & & \\
\hline Spain & ESP & & \\
\hline Sweden & SWE & & \\
\hline Switzerland & $\mathrm{CHE}$ & & \\
\hline United Kingdom & UK & & \\
\hline Canada & CAN & & \\
\hline United States & US & & \\
\hline \multicolumn{2}{|c|}{ East Asian Countries } & & \\
\hline Japan & JPN & & \\
\hline \multicolumn{2}{|l|}{ Oceania } & & \\
\hline Australia & AUS & & \\
\hline New Zealand & NZL & & \\
\hline
\end{tabular}

Notes: The classification of the countries follows the United Nations

(http://www.un.org/en/development/desa/policy/wesp/wesp_current/2012country_class.pdf). 
Table 2: Descriptive Statistics of HP-Filtered Real GDP per Capita, 1870-2012

\begin{tabular}{|c|c|c|c|c|c|c|c|c|}
\hline Series & Obs & $\begin{array}{c}\text { Mean of } \\
\text { absolute value }\end{array}$ & $\begin{array}{l}\text { Standard } \\
\text { Deviation }\end{array}$ & Minimum & Maximum & Skewness & $\begin{array}{c}\text { Excess } \\
\text { kurtosis }\end{array}$ & $\begin{array}{l}\mathrm{ADF} \\
\mathrm{ADF}\end{array}$ \\
\hline$A U T$ & 143 & 0.026269 & 0.056644 & -0.414423 & 0.317223 & $-1.7187^{* *}$ & $26.618^{* *}$ & $-9.993^{* *}$ \\
\hline$B E L$ & 143 & 0.013310 & 0.025125 & -0.196471 & 0.101752 & $-2.7146^{* *}$ & $27.238^{* *}$ & $-9.438^{* *}$ \\
\hline$D E N$ & 143 & 0.015280 & 0.023041 & -0.093649 & 0.103380 & -0.0826 & $5.1708^{* *}$ & $-10.77^{* *}$ \\
\hline$F I N$ & 143 & 0.020129 & 0.029038 & -0.180496 & 0.074274 & $-1.5909 * *$ & $9.3679^{* *}$ & $-8.797^{* *}$ \\
\hline$F R A$ & 143 & 0.022481 & 0.040196 & -0.188010 & 0.150704 & $-1.0817^{* *}$ & $8.3832^{* *}$ & $-9.661^{* *}$ \\
\hline$G E R$ & 143 & 0.025251 & 0.054216 & -0.397063 & 0.269636 & $-2.1737^{* *}$ & $24.440^{* *}$ & $-8.617^{* *}$ \\
\hline$G R C$ & 143 & 0.036969 & 0.063353 & -0.292641 & 0.269098 & -0.3424 & $7.4947^{* *}$ & $-10.06^{* *}$ \\
\hline$I T A$ & 143 & 0.020913 & 0.035484 & -0.269830 & 0.115405 & $-2.7410^{* *}$ & $22.858^{* *}$ & $-8.818^{* *}$ \\
\hline$N E D$ & 143 & 0.022681 & 0.044177 & -0.290409 & 0.112731 & $-3.4546^{* *}$ & $22.276^{* *}$ & $-9.213^{* *}$ \\
\hline NOR & 143 & 0.013861 & 0.021665 & -0.098578 & 0.071494 & $-0.5544^{* *}$ & $5.9134^{* *}$ & $-10.25^{* *}$ \\
\hline$P R T$ & 143 & 0.016937 & 0.023468 & -0.098157 & 0.078764 & -0.1836 & $2.6661^{* *}$ & $-11.95^{* *}$ \\
\hline$E S P$ & 143 & 0.018925 & 0.027814 & -0.096817 & 0.130349 & 0.2990 & $4.1668^{* *}$ & $-9.646^{* *}$ \\
\hline$S W E$ & 143 & 0.013725 & 0.019600 & -0.067767 & 0.076489 & -0.0386 & $2.6587^{* *}$ & $-11.05^{* *}$ \\
\hline$C H E$ & 143 & 0.019677 & 0.027024 & -0.109273 & 0.089844 & -0.3738 & $2.0337^{* *}$ & $-9.341^{* *}$ \\
\hline$U K$ & 143 & 0.014272 & 0.019167 & -0.056669 & 0.064650 & -0.0649 & $0.9472^{*}$ & $-7.713^{* *}$ \\
\hline$C A N$ & 143 & 0.022183 & 0.031525 & -0.123562 & 0.088849 & $-0.4757^{*}$ & $2.2671^{* *}$ & $-8.593^{* *}$ \\
\hline$U S$ & 143 & 0.023838 & 0.035067 & -0.097466 & 0.136312 & 0.2772 & $2.3654^{* *}$ & $-8.253^{* *}$ \\
\hline$A R G$ & 143 & 0.029378 & 0.040096 & -0.133072 & 0.128086 & -0.3524 & $1.5038^{* *}$ & $-10.74^{* *}$ \\
\hline$B R A$ & 143 & 0.017521 & 0.027202 & -0.112409 & 0.118402 & -0.2721 & $4.9915^{* *}$ & $-10.51^{* *}$ \\
\hline$C H L$ & 143 & 0.033926 & 0.049016 & -0.241299 & 0.183961 & $-0.6902^{* *}$ & $4.4891^{* *}$ & $-9.426^{* *}$ \\
\hline$U R U$ & 143 & 0.036376 & 0.048738 & -0.162179 & 0.148226 & 0.0240 & $1.0062 *$ & $-10.20^{* *}$ \\
\hline$I N D$ & 143 & 0.018874 & 0.026554 & -0.092784 & 0.091546 & -0.3593 & $2.3217^{* *}$ & $-15.10^{* *}$ \\
\hline$I D N$ & 143 & 0.020205 & 0.032340 & -0.137678 & 0.183579 & $0.7249^{* *}$ & $8.9229^{* *}$ & $-7.780^{* *}$ \\
\hline$J P N$ & 143 & 0.024999 & 0.044803 & -0.315425 & 0.219798 & $-1.6321^{* *}$ & $20.614^{* *}$ & $-10.76^{* *}$ \\
\hline$S R L$ & 143 & 0.018807 & 0.026115 & -0.089064 & 0.059081 & -0.2676 & $1.1698^{* *}$ & $-10.39^{* *}$ \\
\hline$A U S$ & 143 & 0.016801 & 0.023895 & -0.083695 & 0.082136 & -0.1426 & $1.9231^{* *}$ & $-10.49^{* *}$ \\
\hline$N E Z$ & 143 & 0.022688 & 0.031123 & -0.073131 & 0.096548 & 0.2244 & 0.7262 & $-11.44^{* *}$ \\
\hline average & 143 & 0.021714 & 0.034314 & -0.167112 & 0.131938 & -0.7318 & 8.3160 & \\
\hline
\end{tabular}

Notes: Original series are in logs such that the cyclical components are defined as relative deviations from potential output. Country-specific means of cyclical components are zero. ADF denotes Augmented Dickey Fuller tests with $5 \%(1 \%)$ critical values of $-2.88(-3.48){ }^{*}$ and $* *$ indicate significance at $5 \%$ and $1 \%$ level, respectively. 




